\title{
An Autoantibody with U-specificity in a Patient with Myasthenia Gravis
}

\author{
M. L. Beck, S. H. Butch, W. D. Armstrong, and H. A. Oberman \\ From the Department of Pathology, The University of Michigan, Ann Arbor, Michigan
}

\begin{abstract}
Lack of reactivity of IgG autoantibodies with $\mathbf{R h}_{\text {nu11 }}$ red blood cells does not necessarily imply specificity directed towards the Rh system. Recent reports have indicated that occasionally the autoantibodies of warm antibody type hemolytic anemia may have U-specificity. This report describes an example of auto-anti-U occurring in a patient with myasthenia gravis who had no evidence of hemolysis.
\end{abstract}

Although the majority of autoantibodies associated with warm antibody type autoimmune hemolytic anemia appear to be "non-specific," blood group specificity occasionally can be recognized. This first was demonstrated by Weiner ${ }^{15}$ in 1953 , and confirmed in subsequent reports. 5 With rare exceptions, $6,7,14,17$ such specificity is directed towards the $\mathrm{Rh}$ system; moreover, many of the apparently "non-specific" autoantibodies recognize antigenic material intimately involved in the $R h$ determinants. 4,16

Recently, Nugent et al. ${ }^{11}$ reported a patient with autoimmune hemolytic anemia whose autoantibody reacted in a "nonspecific" manner with cells of common $\mathrm{Rh}$ types, more weakly with $-\mathrm{D}$ - cells and not at all with $\mathrm{Rh}_{\text {null }}$ cells. Subsequent studies revealed the antibody specificity to be anti-U rather than anti-Rh.

Received for publication November 29, 1971; accepted March 13, 1972.
It is now evident that this case does not represent an isolated instance of auto anti-U. Marsh ${ }^{9}$ and his colleagues found complex autoantibody specificities involving $R h$ and $U$ in three of a series of 50 patients with warm antibody autoimmune hemolytic anemia. Blajchman et al. ${ }^{3}$ described two members of a family found to have idiopathic autoimmune hemolytic anemia. The propositi's serum and eluate contained anti-U.

This report describes a further example of autoimmunity involving $U$-specificity. In this patient, however, no evidence of in vivo hemolysis could be found.

\section{Case Report}

A 23-year-old Caucasian man first was seen in 1970 complaining of weakness, diplopia and fatigability. This led to a diagnosis of myasthenia gravis. Serologic studies were not performed until one year later when he was readmitted for thymectomy. A strong positive direct antiglobulin test, found at that time, was due to IgG sensitization. No free antibody was demonstrated in his serum other than a weak, cold-reactive anti-I, no stronger than that encountered in many normal sera. An eluate prepared from the patient's cells yielded anti-U.

Studies performed one week later confirmed the original finding and suggested the additional presence of a "non-specific" autoantibody. Further tests of the patient's serum, performed three months later, revealed a strong "non-specific" component which, following absorption with U-negative cells, left 
anti-U. At no time during the period of observation was the patient anemic. His hemoglobin consistently was above $15.0 \mathrm{~g} / 100 \mathrm{ml}$, and his hematocrit averaged 44 per cent. Reticulocytes comprised no more than 0.9 per cent of the erythrocytes.

\section{Materials and Methods}

Standard blood typing technics were used throughout. Eluates were prepared by the method of Rubin ${ }^{12}$ from EDTA anticoagulated blood. Red blood cells used for antibody identification studies either were from commercially prepared panels or from our own frozen panels.

\section{Results of Serologic Studies}

The direct antiglobulin test was strongly positive with a broad spectrum anti-human globulin serum. The prior addition of human IgG was inhibitory, showing sensitization to be due to IgG globulins. The patient's cells were not agglutinated by rabbit anti-C'3. The patient was typed as $\mathrm{O}$, Rho (D) positive, MS. The anti-s and anti-U typing sera available were reactive only by the indirect antiglobulin technic, thereby precluding their use.

The patient's serum contained a cold-reactive anti-I agglutinin. An eluate prepared from his cells yielded a very strong antibody which reacted with all members of a commercial panel by the indirect antiglobulin technic. No difference in strength of reaction between the various cell samples was noted with either undiluted eluate or eluate diluted 1:25 with saline solution. Two U-negative cell samples that had been stored frozen in glycerol failed to react; a third U-negative cell sample from a commercial source also was non-reactive. In addition, two cell samples of the $R h_{\text {null }}$ phenotype were not agglutinated by the patient's eluate.

A panel of cells, selected for the absence of high incidence antigens was tested with the eluate by the indirect antiglobulin technic. The following cells were all strongly reactive: $\mathbf{L u}(\mathrm{b}-), \quad$ Fy $(\mathrm{a}-\mathrm{b}-), \quad \mathrm{K}+\mathrm{k}-, \quad \mathbf{K p}(\mathrm{a}+\mathrm{b}-)$, Js $(a+b-), K_{o}, T j(a-)$, Vel negative, Cs (a-), Chido negative, Ge negative, and $L a n$ negative. An adult $i$ cell and ten cord blood samples also were strongly reactive. Weaker reactions were obtained with an example of each of the following cell types: -D-, CD-, and $\mathrm{rhG}_{\mathrm{rhG}}$. The results of titration of the eluate against various red blood cells are shown in Table 1.

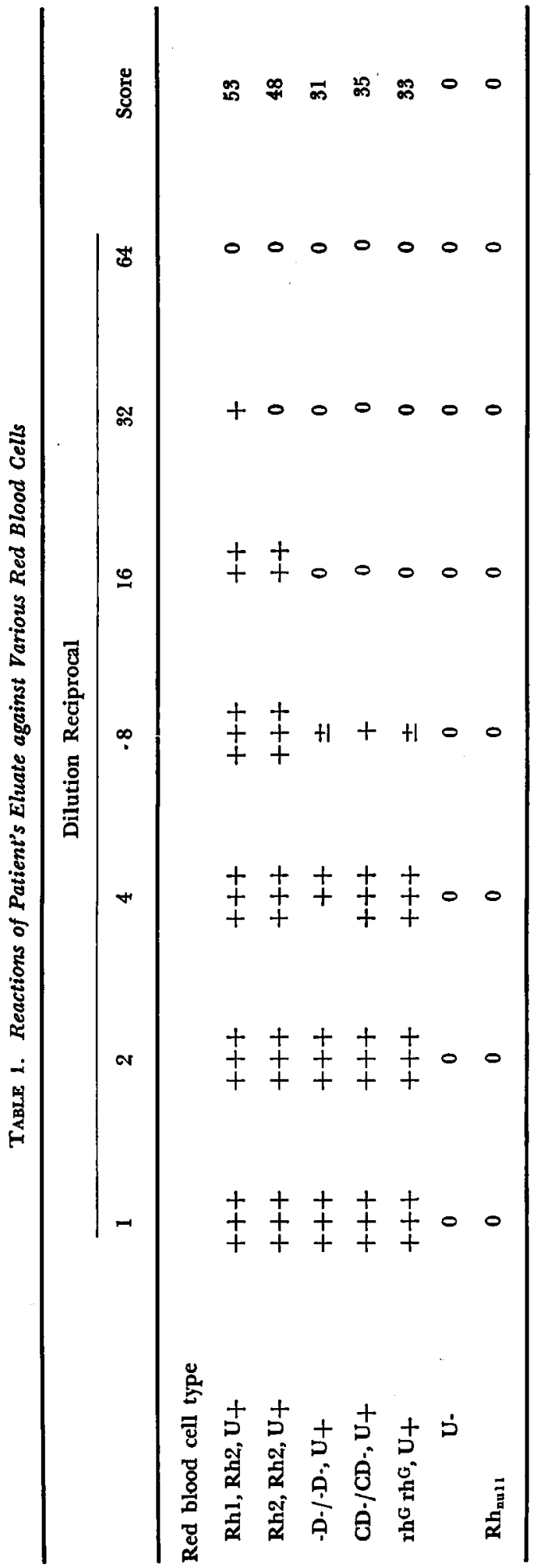


Subsequent serologic investigations three months after the initial studies revealed a change in the specificity of the autoantibody. Whereas the autoantibody initially was monospecific, subsequent studies revealed a "nonspecific" component. Beck et al. 2 have reported sequential changes in autoantibody specificity in a patient with autoimmune hemolytic anemia, and the present patient manifested similar features. Although the "non-specific" antibody reacted only weakly with $R h_{\text {null }}$ cells, it did not have U-specificity. The concurrent presence of anti-U was demonstrated by absorption of the "non-specific" component with U-negative cells; the absorbed serum had anti-U specificity.

\section{Discussion}

The antibody responsible for the positive direct antiglobulin test in this patient represents the second reported example of auto anti-U. Nugent et al.11 recently reported anti-U as a cause of autoimmune hemolytic anemia in an elderly woman, Although the cells of our patient were strongly sensitized, there was no evidence of anemia. In the absence of red blood cell survival studies, we cannot exclude the possibility of a compensated hemolytic process; however, the patient never manifested reticulocytosis.

The observations in this patient support the finding of Nugent $e t$ al. that antibodies reacting with all cells other than $R_{h} h_{\text {null }}$ do not necessarily have Rh-specificity. Nugent et al. ${ }^{11}$ and Marsh et al. ${ }^{9}$ noted that failure of reactivity of autoantibodies with $R h_{\text {null }}$ cells may occasionally be a result of the aberrant $U$ status of these cells. Schmidt et al. ${ }^{13}$ have postulated that the $\mathrm{Rh}$ and $\mathrm{U}$ aberrations found in $R h_{\text {null }}$ cells are a result of abnormality of sequential genes controlling common terminal sugars, giving various specificities depending upon the basic precursor.

We have confirmed the observation of Nugent et al.11 that $-\mathrm{D}$ - cells react more weakly with auto-anti-U than do U-positive red blood cells of normal $\mathrm{Rh}$ phenotypes.
This observation of weakened reactivity was extended to include other $U$-positive cells having the $\mathrm{Rh}$ phenotypes $\mathrm{CD}$ - and $\operatorname{rh}^{\mathrm{G}} \mathbf{r h}$.

The significance of the weak reaction of anti-U with rhG $^{\text {rhG }}$ cells is difficult to assess. The red blood cells used in this study had been frozen in glycerol for nearly two years but their reactivity with other antisera was not modified by storage. We have no reason to believe that prolonged storage alters $U$ antigen activity. ${ }^{10}$ Weak reactions of various anti-Rh sera with fresh rhG cells has been noted by others. ${ }^{1}$ If, as Schmidt suggests, ${ }^{13}$ there is precursor material common to both $\mathrm{Rh}$ and $U$, it is conceivable that there is weakened expression of the $U$ gene in rhGrhG cells.

\section{Acknowledgments}

We wish to express our gratitude to Miss Mija MacIlroy who supplied some of the rare red blood cell samples used in this study.

\section{References}

1. Allen, F. H. and P. H. Tippett: $A$ new $R h$ blood type which reveals the $R h$ antigen $G$. Vox Sang. 3: 321, 1958.

2. Beck, M. L., J. Dixon, and H. A. Oberman: Variation of specificity of autoantibodies in autoimmune hemolytic anemia. Am. J. Clin. Path. 56: 475, 1971.

3. Blajchman, M. A., Y. T. Hui, T. E. Jones, and K. H. Luke: Familial autoimmune haemolytic anaemia with an autoantibody demonstrating U specificity. Proc. 24th Ann. Mtg. Am. Assoc. Blood Banks Chicago, 1971.

4. Celano, M. J. and P. Levine: Anti-LW specificity in autoimmune acquired hemolytic anemia. Transfusion 7:265, 1967.

5. Dacie, J. V.: The Haemolytic Anaemias, 2nd ed. Part II. New York, Grune and Stratton, Inc., 1962, p. 447.

6. Dausset, J. and J. Colombani: The serology and the prognosis of 128 cases of autoimmune hemolytic anemia. Blood 14: 1280, 1959.

7. Flückiger, P., C. Ricci, and C. Usteri: Zur Frage der Blutgruppenspezifität von Autoantikörpern. Acta Haemat. 13: 53, 1955. 
8. Levine, P., R. E. Rosenfield, and J. White: The first example of the $R h$ phenotype $r^{G} G$. Am. J. Hum. Genet. 13: 299, 1961.

9. Marsh, W. L., M. E. Reid, and E. P. Scott: Autoantibodies of $U$ blood group specificity in autoimmune haemolytic anaemia. $\mathrm{Br}$. J. Haemat. In press.

10. - : Personal communication.

I1. Nugent, M. E., K. I. Colledge, and W. L. Marsh: Auto-immune hemolytic anemia caused by anti-U. Vox Sang. In press.

12. Rubin, H.: Antibody elution from red blood cells. J. Clin. Path. 16: 70, 1963.

13. Schmidt, P. J., M. M. Lostumbo, C. T. English, and O. B. Hunter: Aberrant U blood group accompanying $R h_{\text {nu11 }}$. Transfusion 7: 33, 1967.

14. Van Loghem, J. J. and M. van der Hart: Varieties of specific auto-antibodies in acquired haemolytic anaemia. Vox Sang. 4: 2, 1954.

15. Weiner, W., D. A. Battey, T. E. Cleghorn, F. G. W. Marson, and M. J. Meynell: Serological finding in a case of haemolytic an- anaemia; with some general observations on the pathogenesis of this syndrome. Br. Med. J. 2: $125,1953$.

16. — and G. H. Vos: Serology of acquired hemolytic anemias. Blood 22: 606, 1963.

17. Yokoyama, M., D. T. Eith, and M. Bowman: The first example of auto-anti-Xga. Vox Sang. 12: 138, 1967.

Malcolm L. Beck, FIMLT, Research Technologist, Blood Bank Section, Department of Pathology, University of Michigan Medical Center.

Suzanne H. Butch, MT (ASCP), Medical Technologist, Blood Bank Section, Department of Pathology, University of Michigan Medical Center.

William D. Armstrong, M.D., Resident II, Department of Pathology, University of Michigan Medical Center.

Harold A. Oberman, M. D., Professor of Pathology, Medical Director, Blood Bank, University of Michigan Medical Center, 1335 E. Catherine St., Ann Arbor, Mich. 48104. 